\title{
VIII.
}

Aus der chirurgischen Klinik zu Göttingen.

\section{Die Lageverhältnisse des Cöcum und ihre Beziehung zur Entstehung von äusseren Cöcalbrüchen.

\author{
Von
}

Dr. Hildebrand, Privatdocent.

(Mit 4 Abbildungen.)

Zum Zustandekommen eines Bruches sind bekanntermaassen zwei Dinge nöthig: die Bildung eines Bruchsackes, und das Eintreten eines Eingeweides in denselben. Während jenes erste Moment naturgemäss viel Studium und Bearbeitung gefunden hat, weil es das wichtigste ist, ist das zweite viel weniger beachtet worden, was ja daraus ganz erklärlich ist, dass zum Eintreten des Darmes in einen Bruchsack bei der Mobilität der meisten Darmabschnitte keine besonderen Motoren nöthig sind, als einfacher Druck auf den Bauchinhalt. Nur für die Darmtheile ist diese Frage nicht so ohne Weiteres gelöst, welche normaler Weise an ihrer Lagerungsstelle fester und kürzer fixirt sind, wie z. B. das Cöcum, das Col. asc. u. s. w. Mehrere darauf bezügliche Beobachtungen, die ich im vorigen Jahre machte, lenkten mein Interesse auf diesen Punkt; sie wurden der Anstoss, mich eingehender mit dieser Frage zu beschäftigen. Dabei fand ich, dass zwar in der französischen und englischen Literatur mehrere ausfuhrlichere Arbeiten niedergelegt sind, während in der neueren deutschen Literatur wenig Zusammenfassendes vorhanden, dass aber trotzdem nicht alle Fragen gelöst sind. Ich versuchte deshalb nicht nur mir dartiber Klarheit zu verschaffen, sondern auch die Dinge zusammenfassend darzustellen. Dementsprechend beginne ich mit der Entwicklungsgeschichte des Coecum, dann folgen die normalen Lageverhältnisse, dann die pathologischen und schliesslich die Hernien.

Etwa ${ }^{1}$ ) in der 5. Woche des fötalen Lebens tritt an dem hin-

1) Diesem Abschnitt liegen die Schilderungen von Kölliker und Hertwig zu Grunde. 
teren Schenkel der Darmschleife, in geringer Entfernung vom Scheitel derselben, eine kleine Anschwellung auf, die bald einen kleinen stumpfen Anhang treibt. Dieser Anhang ist die Anlage des Cöcum mit dem Proc. vermiformis. Die Trennung von Dünndarm und Dickdarm nimmt immer mehr zu, in der 6. Woche ist sie deutlich. Beide Theile, namentlich aber der Diunndarm, fahren vom Ende des 2. Monats an fort stark in die Länge $z \mathfrak{u}$ wachsen und sich in Windungen zu legen. Hierbei beginnt eine Drehung der beiden Schenkel der Darmschleife um einander, so dass der hintere Schenkel erst nach links und dann über den anderen und nach rechts zu liegen kommt. Es geräth also der Anfangstheil des Dickdarms oder das Cöcum ganz auf die rechte Seite des Körpers nach oben unter die Leber; von hier läuft das Colon in querer Richtung uiber das Duodenum unter dem Magen zur Milzgegend heriber, biegt dann scharf um und steigt nach der linken Beckengegend herab. Der verlängerte Dickdarm bildet also eine grosse Schleife, die bis an den Magen reicht und dort vom grossen Netz bedeckt ist. Somit sind schon im 3. Monat am Dickdarm das Cöcum, das Colon transversum und descendens unterscheidbar. Ein Colon ascendens fehlt noch. Das Colon descendens ist gut ausgeprägt, das Colon transversum ist kürzer, reicht kaum über die Mittellinie, während das Cöcum fast genau in der Mittellinie steht. Das Colon ascendens bildet sich erst in den folgenden Monaten dadurch aus, dass der anfangs unter der Leber befindliche Blinddarm allmählich eine tiefere Lage einnimmt, so dass er sich im 7. Monat unterhalb der Niere findet und vom 8. Monat an über den Darmbeinkamm herabsteigt. In dieser Zeit hat der Blinddarm an Länge zugenommen und stellt gegen Ende der Schwangerschaft einen ziemlich beträchtlichen Anhang an der Uebergangsstelle des Dünndarms und Dickdarms dar.

Ist der Blinddarm in der Darmbeingrube angelangt, dann hat unter normalen Verhältnissen seine Wanderung ein Ende. Er bleibt da liegen, und man findet ihn in der postfötalen Zeit normaler Weise über dem Musc. iliac. int., mit dessen Fascie er aber nicht in unmittelbarer Berïhrung steht. Er stellt einen sowohl in Länge, als Form sehr veränderlichen Körpertheil dar. Wenn man nur das zum Cöcum rechnet, was unterhalb der Einmündungsstelle des Ileum gelegen ist, so ist er der weiteste, nicht selten sackartig aufgetriebene Theil des Dickdarms. Seine Länge schwankt nach Henle zwischen 2,7 und $11 \mathrm{Cm}$., nach Luschka zwischen 1 und 4 Zoll. Je nach dieser seiner Länge ist der Blinddarm mehr oder weniger medianwärts gekrümmt, so dass sein abgerundetes Ende nach dieser Rich- 
tung gekehrt ist. $\mathrm{Ab}$ und zu verengt er sich auch trichterförmig und ganz allmählich zum Proc. vermiformis, wie dies beim Fötus normal ist.

Die Beziehungen des Blinddarms zu seiner Umgebung, namentlich zum Peritoneum, sind nun vielfach Gegenstand der Untersuchung gewesen; namentlich wurde die Frage früher in der Literatur viel discutirt, ob das Cöcum ganz oder nur theilweise vom Bauchfell umkleidet sei, auch selbst dann noch, als man die Bezeichnung Cöcum für den Theil des Dickdarms reservirte, der unterhalb der Ileocöcalmündung gelegen. Durch vielfältige Untersuchung namentlich von Siegmund Schultze, Bardeleben, Luschka u.s.w. ist die Sache jedoch nun schon vor längerer Zeit sicher festgestellt. Luschka äussert sich darüber folgendermaassen:

„Als ganz gewöhnliches, mit Entschiedenheit als die Regel zu bezeichnendes Verhalten muss ich die vollständige peritoneale Umhüllung des Blinddarms ansehen, indem ich dasselbe sowohl bei der Untersuchung vom Peritonealcavum aus fast immer zu constatiren vermochte, als auch bei der Betrachtung von der Aussenseite her an dem vollkommen isolirten Peritonealsacke. Dort vermag man den Blinddarm zu umgreifen, in die Höhe zu heben und seitlich zu verschieben, hier kann man ihn obne Verletzung des Bauchfells nicht eröffnen, was doch so leicht am Colon ascendens geschehen kann." Ganz in gleicher Weise sprechen sich Bardeleben, Hyrtle, Henle und Andere aus.

Auch neuere Untersuchungen bestätigten dieses Verbältniss. Trèves hat bei Untersuchung von 100 Leichen immer das Cöcum vollständig frei auf der Hinterseite gesehen. Nach ihm wendet sich das Bauchfall etwa $11 \mathrm{Cm}$. vom Gipfel des Cöcum plötzlich um, um auf die Fossa iliaca uberzugehen. Auch Mérigot de Treigny fand dasselbe. In gleicher Weise constatirte er diese Verhältnisse auch bei einer grösseren Anzahl von Neugeborenen. Tuffier fand unter 120 Leichen nur 9, bei welchen das obere und hintere Drittel des Cöcum entblösst von Serosa war. Das waren Erwachsene und Greise. Sieht man sich diese Dinge an einer Reihe von Leichen an, so ist es schwer zu begreifen, wie überhaupt Zweifel an der Thatsache der vollständigen Peritonealbekleidung des Cöcum aufkommen konnten. Freilich besteht innerhalb der normalen Grenzen eine grosse Verschiedenheit bezüglich der Länge des freien Theiles. Trèves fand nach den oben mitgetheilten Beobachtungen als Mittel etwa $11 \mathrm{Cm}$. bei Erwachsenen. Ich habe an einer ganzen Reihe von Leichen mir die Verhältnisse auf diesen Punkt hin angesehen; danach will es mir scheinen, als ob bei Kindern der freie Theil verhältnissmässig viel grösser 
sei, als bei Erwachsenen; wiederbolt konnte ich ihn bei Kindern von etwa 5 Jahren circa $10 \mathrm{Cm}$. lang finden und bei erwachsenen Männern nur $4-5 \mathrm{Cm}$. lang, bei im Uebrigen ganz gleichem Befund. Meist liess sich das Cöcum obne besondere Ausdehnung desselben bei Kindern leicht an den rechten, meist auch an den linken Leistenkanal bringen, während bei Erwachsenen dies nicht möglich war. Wiederholt hing es in das kleine Becken hinein.

Nun erreicht aber nach Tarenetzki das Cöcum im Alter seine grösste relative Länge, und zwar sind nach ihm die Längenverhältnisse

bei Embryonen von 6 Monaten - Geburt bei einer mittleren Körperlänge von ..... $32,3 \mathrm{Cm}$.

mittlere Länge des Cöcum . . . 0, $0,7=$

Kinder bis zum 14. Jahre:

Körperlänge . . . . $=60,5 \mathrm{Cm}$.

Cöcum ........ $=2,6=$

Erwachsene bis zum 49. Jahre:

Körperlänge . . . . $=85,0=$

Cöcum ....... $=4,5=$

Erwachsene bis zum 80. Jahre:

Körperlänge . . . . $=83,2$

Cöcum ....... $=4,5=$

Es geht daraus hervor, dass bei Kindern das Colon ascendens häufig noch in seinem unteren Theile frei ist, während bei Erwachsenen nur noch das Cöcum frei ist. Es hat also ein Vorgang statt, der zur Fixirung des unteren Theils des Col. ascendens führt.

Nach Treitz besteht die Fixation des Col. ascend. darin, dass die schneller als das Colon wachsenden Bauchwände einen Theil des Peritonealtaberzuges des Darmes und die hintere Platte seines Gekröses zu ihrer Auskleidung requiriren, dass also der ganze Vorgang ein rein mechanischer sei und gewissermassen in einem Abwickeln des Bauchfëlls von der hinteren Fläche des Colon bestehe. Luschka und Andere sind derselben Meinung, Waldeyer sprieht sich jedoch dagegen aus und bält das schnellere Wachsthum der Nieren und die Translocation eines Theils des Peritoneum zu ibrer Bedeekung für die Ursache. Im Gegensatz hierzu nehmen Langer und Toldt ein wirkliches Verwachsen zweier früher freien Peritonealfächen an, wobei die Endothelbekleidung zu Grunde geht und nur die bindegewebige Basis des Bauchfells zurückbleibt. Tarenetzki hält Beides für möglich, glaubt jedoch mehr an das letztere, die Verwachsung.

Ebenso sagt Hertwig in seiner Entwicklungsgeschichte: „Auch vom Aufhängeband vom Cöcum und vom auf- und absteigenden Schenkel des Dickdarms tritt eine Verwachsung mit dem Bauchfell des 
Rumpfes bald in mehr, bald in minder ausgedehnter Weise ein" u. s. w. Dieser Ansicht möchte ich mich auch anschliessen. Vielleicht sprechen aber auch Differenzen im Wachsthum des Cöcum und des Beckens dabei mit; das wird wahrscheinlich gemacht dadurch, dass zweifellos der freie Theil des Colon und des Cöcum bei Kindern viel grösser ist im Vergleich zum Becken, als bei Erwachsenen. Bei den meisten Kindern liess sich, wie ich schon erwähnte, das Cöcum ohne besondere Ausdehnung desselben leicht nach dem rechten, meist auch nach dem linken Leistenkanal bringen, während bei Erwachsenen, die ein frei bewegliches Cöcum hatten, dies für gewöhnlich nicht möglich war, nur bei sehr ausgedehntem Zustand. Wiederholt fand ich bei Kindern das Cöcum ins kleine Becken hineinhängend.

Während das Cöcum also gewöhnlich ganz frei ist, ist der daranstossende Theil des Colon ascendens fest auf der Unterlage fixirt durch das Bauchfell und meist zu zwei Drittel vom Peritoneum bedeckt. Dadurch findet auch das Cöcum seinen Fixationspunkt gegen Verschiebung von oben nach unten. Ausserdem aber, dass das Cöcum indirect durch seine Fortsetzung in das fixirte Colon ascendens bis zu einem gewissen Grade an Lageveränderungen verhindert ist, hat es noch einige Fixationsapparate. Sie werden schon von Scarpa erwähnt; er sagt S. 165: „Der Blinddarm und der Anfang des dicken Darmes sind zwar mit dem grossen Sacke des Bauchfells in der rechten Weichen- und Lendengegend durch zwei Falten des Bauchfells sehr genau vereinigt, von denen die eine sich an das Darmbein, die andere an dem äusseren Rande des grossen runden Lendenmuskels (ileopsoas) befestigt". Noch ausführlicher beschreibt sie Tuffier, dem wir ausgedehnte anatomische Untersuchungen daruber verdanken. Auch Mérigot de Treigny hat sie stets gefunden. Das wichtigste ist das obere, das Tuffier so charakterisirt: „Le ligament est un repli de la séreuse péritonéale. Il s'insère en haut sur la paroi de la fosse lombaire immédiatement au dessous du rein ou même sur son extremité inférieure, de là il vient se perdre sur la paroi latérale externe du côlon ascendant à son union avec le coecum. Il est donc dirigé de haut en bas et d'arrière en avant présentant deux faces l'une supérieure et antérieure, l'autre postérieure et inférieure. C'est l'obstacle principal à l'abaissement et lorsqu'on tire l'intestin en bas et dedans du coecum on voit cette bride se soulever, se tendre et déterminer sur la face externe et jus'que sur la face antérieure du coecum des plis radiés." Als unteres Ligament bezeicbnet er: l'insertion du mésentère à la fosse iliaque und beschreibt als solches: un pli de la séreuse s'étendant de la fosse iliaque sur le bord gauche 
du coecum et sur le mésentère. Dieses untere Band verhindert, dass sich das Cöcum von dem peritonealen Ueberzug bei der Ausdehnung abtrennt. Und schliesslich verhindert seiner Meinung nach das Mésentère fixe das Cöcum, nach rechts sich zu verschieben. Das untere Ligament ist weniger dick und fest, es hat die Formen einer dreieckigen Platte, deren Gipfel zwischen der Wurzel des Wurmfortsatzes und der Einmuindungsstelle des Ileum in das Cöcum liegt. Sein vorderer Rand entspricht dem Wurmfortsatz, sein hinterer dem Zellgewebe der Fossa iliaca, und sein unterer Rand ist frei und concav. Dieses untere Ligament ist nun wohl doch nichts Anderes weiter, als die eine Wand der Fossa subcoecalis, wie sie schon Luschka ausführlich beschrieben hat. Lu schk a schildert diese Fossa ileocoecalis so: „Sie ist am medianen Umfange der Stelle des äusserlichen $\mathrm{Zu}$ sammenstossens jener Darmstücke angebracht, bietet eine rundliche Form und beim erwachsenen Menschen eine durchschnittliche Tiefe von $3 \mathrm{Cm}$. dar. Nach aussen hin ist sie begrenzt durch das Ende des Dünndarmes, nach innen durch das Gekröse des wurmförmigen Fortsatzes, nach oben durch eine 1,5 bis $2 \mathrm{Cm}$. bohe Falte, welche eine Fortsetzung des Mesenteriolum proc. vermiformis darstellt und in die mediane Platte desjenigen Abschnitts von Gekröse übergeht, welcher sich an die Concavität des Diunndarmendes anschliesst. Die untere, der Spitze des Blinddarms zugekehrte Wand ist viel niedriger und durchschnittlich $1 \mathrm{Cm}$. hoch" u. s. w. Auch Tuffier bespricht diese Fossa ileocoecalis genauer. Was Luschka also einfach anatomisch als Wand der Fossa ileocoecalis beschrieben hat, das schied Tuffier physiologisch, indem er ihm einen Namen nach dieser seiner Function giebt. Es sind aber dieselben Dinge.

Dies sind die normalen anatomischen Verhältnisse des Cöcum. $\mathrm{Da}$ sie die Basis für die Beurtheilung der pathologischen Verhältnisse sind, habe ich sie in solcher Ausfubrlichkeit hier erwähnt, obgleich darin nicht viel Neues gesagt ist. Man sieht aus dem Mitgetheilten, dass unter gewöhnlichen Verbältnissen das Cöcum nicht leicht zum Inhalt eines Bruches werden kann, dass also Veränderungen des Normalen hinzukommen muissen, welche das Cöcum geeignet machen, in einen Bruchsack einzutreten. - Veränderungen der Grösse oder der Lage desselben werden durch die mannigfachsten Ursachen hervorgerufen. Wenn wir uns nun diese Veränderungen a priori klar zu machen und in Kategorien zu bringen suchen, so können wir sie eintheilen in

I. angeborene Anomalien des Cöcum:

a) abnorme Grösse, abnorme Länge; 
b) abnorme Lage:

1. Durch Stehenbleiben auf einer fötalen Stufe;

2. durch Anomalien seiner Befestigung (sebr langes Mesenterium, sehr lange Ligamente);

3. durch Verwachsungen mit anderen Organen in der fötalen Zeit (mit dem Testis) und Zug durch diese Organe;

II. später entstandene Anomalien, Lageveränderungen dureh Zng;

a) des Bauchfells, des Hodens;

b) anderer Darmtheile;

c) durch entzündliche Verwachsungen.

So finden sich a priori eine ganze Reihe von Momenten, von denen man sich vorstellen kann, dass sie das Cöcum geeignet machen, Bruchinhalt zu werden. Diesen aprioristisch als möglich hingestellten Ursachen möchte ich nun gegenüberstellen, was sich als realiter vorhanden, als beobachtet erwiesen hat. Zur Feststellung dieser Dinge müssen wir zunächst betrachten, was überhaupt über Anomalien der Grösse und namentlich der Lage des Cöcum beobachtet und bekannt ist.

Abnorme Grösse des Cöcum, wenigstens so bedeutende, dass es ohne Weiteres zum Inhalt eines Bruches werden konnte, babe ich nirgends notirt gefunden. Dagegen variirt die Lage desselben aus mannigfaltigen Gründen sehr stark. Innerhalb des Normalen liegen wohl die Lageveränderungen, die nicht constant, sondern von der Füllung des Cöcum abhängig sind. Es sind also vorü bergehende Lageveränderungen, deren Ursache die verschieden starke Ausdebnung des Darmes ist. Engel ist es hauptsächlich, der sich mit diesen Veränderungen der Lage des Cöcum beschäftigt hat. Er fand, dass bei mittlerer Ausdehnung durch Darmgase der Blinddarm ungefähr bis zum inneren Rande des Ileopsoas reicht; er liegt dann unmittelbar an der vorderen Bauchwand in der Inguinalgegend, die eine Fascia longit. nach aussen wendend und nur am untersten Theile etwas nach vorn. Das Bauchfell gelangt dann obne Faltenbildung von der Bauchwand zum Blinddarm, und das Ileum mündet unter verschiedenen Winkeln in den Blinddarm. Das die gewöhnliche Lage, wie sie bei Gesunden vorkommt. Ist dagegen der Blinddarm stark zusammengezogen, dann liegt sein Blindsack in der Höhe des Darmbeinkammes, der Blinddarm ist ganz von dünnen Gedärmen gedeckt, und das Ileum geht von ihm aus in der Richtung der eigenen Axe eine Strecke nach unten. Ist der Blinddarm stark ausgedehnt und zwar durch Gas, dann kann sein unteres Ende die Symphysis 
ossis pubis erreichen, ja oberhalb der Schamfuge, hinter der Linea alba, liegen. Der ausgedehnte Blinddarm berührt unmittelbar und gewöhnlich mit einer sehr breiten Fläche die vordere Bauchwand, daher erscheint die seitliche Unterbauchgegend ausgefullt oder gewölbt, ja bei dünnen und schlaffen Bauchwänden lassen sich wohl die Contouren des Blinddarms durchfühlen. Jeder Druck auf die innere Hifftbein- und Leistengegend kann eine Verschiebung des Blinddarminhalts zur Folge haben. Ist der Blinddarm mit dem grossen Netz verwachsen, so kann er in solchem Zustande grösster Ausdehnung sogar gerade hinter dem Nabel zu liegen kommen. Ist die starke Ausdehnung des Blinddarms nicht durch Gase bedingt, sondern durch einen breiigen Inhalt, dann bängt derselbe gewöhnlich in die Beckenhöhle hinein. Auf 100 Leichen Erwachsener seien zu rechnen: 10 mal mittlere Lage des Blinddarms, 28 mal Lagerung hoch über dem Psoas, 30 mal Lagerung oberhalb der Symphysis pubis, 8 mal Lagerung tief im Becken, 4 mal Lagerung in der Gegend des Nabels. In gleicher Weise, wie die Ansammlung von Gasen ausdehnend auf das Cöcum und damit dislocirend wirkt, wirkt natürlich auch die Ansammlung von Koth. Ist diese chronisch vorhanden, dann ist es denkbar, dass ein Heruntertreten des Blinddarms begünstigt wird, namentlich wenn die Bauchdecken schlaff sind und ein dauernder Druck auf das Abdomen ausgelibt wird.

Alle diese Momente treten jedoch vollständig zurïck gegen andere, welche ich jetzt besprechen will. Der Blinddarm zeigt mancherlei, theils in der Entwicklung begründete, theils später entstandene Lagerungsanomalien. So kann z. B. das Herabsteigen des Cöcum die normalen Grenzen tiberschreiten und bis zum unmittelbaren Contact mit dem Cruralring u. s. w. führen.

Weiter ist daran zu erinnern, dass in einer gewissen Periode des fötalen Lebens das Cöcum noch in einer Richtung mit dem Colon transversum liegt und nur sehr allmählich die mehr verticale Stellung und seine Beziehung zum rechten inneren Darmbeinmuskel annimmt. Daraus erklären sich wohl die Fälle, in welchen das Cöcum auf dem Bauche des Psoas major ruhte oder gegen die Mittelebene des Bauchraumes hereingerückt war, wovon Roser zwei Fälle anführt: 1) Cöcum und Colon ascendens beträchtlich gegen die Mittellinie berubergerückt, so dass das Colon ascendens hart an der Wirbelsäule hin auflief; 2) Cöcum gerade vor dem Promontorium und Colon ascendens in der Mittellinie. In selteneren Fällen bleibt also das ursprüngliche Lagerungsverhältniss stationär und kann dann zu merkwürdigen Dis. locationen Veranlassung geben. So beobachtete Engel z. B. einen 
Fall, wo das Cöcum zwischen dem rechten Leberlappen und dem Zwerchfell eingeschoben war. Auch Trèves sah in zwei Fällen das Cöcum horizontal unter der Leber liegen, in einer Falte, die sich in das Mesocolon transversum fortsetzte. Die Insertionslinie des Mesenterium batte in diesem Falle eine fast horizontale Richtung, und Roser fand das Cöcum nach rechts und oben gelagert, so dass sich der Proc. vermiformis nach hinten gegen die Lumbargegend und den Musc. quadratus lumborum gekehrt hatte. Andererseits können aber auch andere fötale Verhältnisse sich erhalten, die eine anormale Lage des Cöcum bedingen können und bedingen. Ich erwähnte schon, dass das Cöcum indirect seine Fixation dadurch bekäme, dass das Colon mit seiner Hinterwand innig mit der Rumpfwand zusammenhinge; daraus geht hervor, dass es für die Mobilität des Cöcum und daraus resultirende Lageveränderungen von grosser Wichtigkeit sein muss, in welcher Weise sich das Mesenterium des Dickdarms entwickelt. Der Dickdarm besitzt nach Hertwig noch im 3. Monat ein sehr langes, von der Wirbelsäule ausgehendes Aufhängeband. Auch am Aufhängeband vom Cöcum und vom auf- und absteigenden Schenkel des Dickdarms tritt eine Verwachsung mit dem Bauchfell der Rumpfwand bald in mebr, bald in minder ausgedehnter Weise ein. Es sitzen daher die genannten Darmtheile beim Erwachsenen bald mit ibrer hinteren Wand breit der Rumpfwand auf, bald sind sie durch ein mehr oder minder kurzes Mesenterium befestigt. Nach Ta r e net z k i dagegen ist bei älteren Embryonen des 5. Embryonalmonats nicht nur das ganze Colon ascendens und der grösste Theil seines Mesenterium bis gegen das Ileum herab fest mit der Niere, dem Duodenum und der hinteren Bauchwand verwachsen, sondern auch die hintere Fläche des Cöcum und das erste Drittel des Wurmfortsatzes, je nach der Lage mit dem Peritoneum parietale, dem Musc. quadr. lumb., der Fossa iliae, dem Musc. psoas mes. verlöthet. Vom 5. Monat an bis zur Geburt ginge wieder eine Lösung der Verwachsung vor sich durch stärkeres Wachsthum des Darmes. Wenzel Gruber fasst dieses Vorkommen eines mehr oder weniger langen und weiten Mesocolon ascendens bei völligem Geschiedensein vom Mesenterium des Dünndarms als eine Bildungshemmung auf. Er sagt dartiber: „Diese kommt bisweilen vor, und es ist derselben bei den Anatomen hier und da gedacht. Ich habe sie öfters und bei Individuen aus den verschiedensten Lebensperioden gesehen. Den mir bis jetzt vorgekommenen höchsten Grad dieser Bildung sah ich bei der Section einer Leiche eines Mannes, welcher mit einer rechtsseitigen Hernia proc. vagin. bahaftet und an innerer Incarceration gestorben war. Das Mesocolon 
ascendens war von seinem Ausgange vom seitlichen Theile der hinteren Bauchwand vor der rechten Niere bis zu seiner Anheftung an das Colon und das grosse Cöcum, um die rechte Hälfte des Colon transversum, welche als eine Schlinge herabhing, spiralförmig und zwar zuerst vorn von rechts nach links, dann hinten von links nach rechts aufgerollt", u. s. w. Am Schluss seiner Arbeit erwähnt er eine Anzahl von Fällen, in denen ein Mesenterium für das Colon ascendens vorhanden war, und gedenkt eines Falles von Erichsen, in dem ein langes Mesocolon sich vorfand und das Cöcum weit nach links verlagert war.

Auch Roser führt zwei Fälle an: 1. Blinddarm an einem Mesenterium mitten in der Bauchhöhle frei flottirend, dagegen war der unterste Theil des Dünndarms einige Zoll weit aus dem Peritonealüberzug herausgeschoben; er verlief hinter dem Peritoneum auf dem Psoas und lliacus ohne Peritonealiuberzug.

2. Cö́cum freiliegend gegen die Mittellinie, das Colon ascendens und descendens mit vollkommenem Peritonealüberzug und sogar einem zollbreiten Mesocolon versehen.

Ausser dieser Form erwähnt Gruber noch eine zweite, bei welcher ein Mesenterium commune für den ganzen Darm vorhanden ist. Ich führe die Fälle hier an, da sie doch für unsere Frage ein grosses Interesse haben.

Fall 1. Linksseitige Lage des ganzen Dickdarms. Mangel des Mesenterium im gewöhnlichen Sinne. Mesenterium commune für den Dünndarm und Dickdarm rom Cöcum bis zur Flex. lienal.

Fall 2. Lage des Dickdarms unter und hinter dem Dünndarm vor der Wirbelsäule und im grossen und kleinen Becken. Befestigung des völlig ausgebildeten Darmkanals an die hintere Bauch- und Beckenwand durch ein einziges, mit seiner Wurzel vor der Wirbelsäule und vor dem Kreuzbein fast vertical absteigendes, dem Gekröse des Mitteldarmes und Enddarmes eines Embryo etwa im vierten Monat analoges Mesenterium. Das Jejunum und Ileum mit einem dem Cöenm, Colon ascendens und Colon transversum entsprechenden Abschnitte des Dickdarms können aufwärts und seitlich aus der Bauchhöhle herausgeschlagen werden. Die Regio iliaca vom Dickdarm leer. Dickdarm beginnt in der Fossa iliaca dextr. und setzt sich durch die kleine Beckenhöhle iuber der Flexura sigmoid. und der Harnblase mit dem von den Dünndarmschlingen unbedeckten ersten Abschnitte in die Fossa iliac. sin. quer hiniber. Dieser Abschnitt entspricht dem Cöcum und Colon ascendens. Das Cöcum liegt in der Fossa iliaca und ist so umgekehrt, dass sein sonst hinterer Umfang nach vorn, sein sonst äusserer Umfang nach unten, sein unteres blindes Ende nach rechts sieht. Es ist $3 \mathrm{Zoll}$ lang. Der Process. vermiformis liegt daher unter der Einsenkung des Ileum in das Colon auf diesem und dem Cöcum, nicht binter demselben. -- „Der Darmkanal hat, an der Flexura 
duoden.-jejunalis angefangen bis zur zweiten Abtheilung des Rectum herab, nur ein einziges gemeinschaftliches Gekröse: Mesenterium commune."

F all 3. Mangel des Mesocolon ascendens im gewöhnlichen Sinne und Mangel jeder Anheftung des Colon ascendens mit dem Cöcum an der rechten Niere und dem rechten Muscul. iliac. int. Freies Hängen des Colon ascendens mit dem Cöcum am rechten Rande des mit seiner Wurzel vor der Wirbelsäule fast transversal befestigten Mesenterium des Dünndarms.

Das Cöcum 3 Zoll lang, Colon ascendens 9 Zoll. Sie hängen in der Regio und Fossa iliac. und vor dem Scheitel der Flexura sigm. bis zum rechten Arcus crur. frei herab. Das vom Peritoneum im ganzen Umfange abgezogene Colon ascendens hängt am Mesenterium des Diunndarms. Von der vorderen Fläche des Mesenteriolum proc. vermif. geht eine am oberen freien Rande halbmondförmig ausgeschnittene Bauchfellfalte zum Cöcum und zum freien Rande des Ileumendes, um eine sehr weite Fossa ileocoecal. zu bilden. Durch das Aufgehängtsein des Colon ascend. an dem Mesenterium erhält dasselbe und das Cöcum eine ganz abnorme freie Beweglichkeit.

In diesen Fällen handelt es sich also um ein Mesenterium commune für den ganzen Darm. Gruber fand dieses Mesenterium commune bei Föten vom 7. Monat an, bei Kindern, Knaben, Jünglingen, Männern; bis zum Jahre 1868 hatte er 13 Fälle davon gesammelt.

Auch diese Fälle werden von ihm als Bildungshemmung aufgefasst, und zwar besteht dieselbe in Reduction aller oder einiger Mesenterien des Darmkanals auf ein einziges oder doch nur auf wenigere, rïcksichtlich ihrer Grösse mehr durch Excess als Mangel von den Mesenterien der Individuen gleichen Alters u. s. w. sich auszeichnende Mesenterien. Dieselbe ist im Stehenbleiben der Mesenterien auf verschiedenen früheren Bildungsstufen begründet: dafür spricht auch die Ansicht Toldt's, da nach ibm im 6. Monat die Selbständigkeit des Mesenterium des Dünndarms beginnt, während vorber ein Mesenterium commune vorhanden war.

Auch Rokitanzki erwähnt das Vorkommen eines langen Gekröses, das zuweilen als Bildungsfehler in Form eines über einer stielförmigen Wurzel sich entfaltenden Mesenterium vorkommt, welches in ein loses Mesenteriolum ascendens sich fortsetzt. Ebenso findet sich eine Beobachtung bei Treck, welcher bei einem neugeborenen Knaben ein ganz ähnliches Mesenterium commune beobachtete; F a rabo e af konnte einen Fall constatiren, wo der Darm die fötale Stellang noch hatte, die Art. mesent. sup. war nach hinten vom IntestinalKanal geblieben, und der ganze Dickdarm zusammen mit der unteren Partie der Abdominalhöhle hatte ein Mesenterium identisch mit dem des Dünndarms. Hervey beobachtete einen etwas weiter vorgeschrittenen Fall. Cöcum, Colon ascendens, Colon transversum fanden 
sich gemischt mit der Masse des Dünndarms und geheftet an dasselbe Mesenterium. Diese Organe lagen unter dem Magen. Manchmal ist die Fixirung des Dickdarms nur am oberen Theil fertig, und der Rest, ebenso wie das Cöcum, sind noch mobit und an das Mesenterium geheftet, dessen hinterer Rand noch transversal läuft. Godle e konnte dies an einem Neugeborenen beobachten. Murray sah an der Leiche eines jungen Mannes 6-7 Zoll Ileum, umgeben von einer completen peritonealen Scheide, die es gemeinschaftlich mit dem Cöcum und dem Colon ascendens hatte. An einem $7 \frac{1}{2}$ monatlichen Fötus machte Mèrigot die Beobachtung, dass das Mesenterium auf das Colon ascendens bis zu $2 \mathrm{Cm}$. vom Darmbeinkamm ïberging, derart, dass das Colon und Ileum Theil hatte an einer grossen Schlinge, analog denen des Dünndarms. In einem Fall von M. Chaput erreichte das Mesenterium fast die Mitte des Colon ascendens. Auch Richard sagt, er hätte 3 oder 4 analoge Fälle gesehen.

Viel häufiger aber als diese Anomalien kommen Unregelmässigkeiten in der Lage des Blinddarms durch abnorme Verwachsungen mit anderen Organen vor. Namentlich der Hoden spielt hier eine grosse Rolle, wie ja ohne Weiteres aus der ursprünglichen Lage und der späteren Veränderung derselben klar ist. Bekanntlich haben die Geschlechtsorgane ursprünglich ihre Lage zu beiden Seiten der Lendenwirbelsäule. Im 3. Monat finden wir sie schon im grossen Becken, im 5. und 6. an der Innenseite der vorderen Bauchwand, dicht am inneren Leistenring. Im 8. Monat erfolgt gewöhnlich der Eintritt in den Leistenkanal, im 9. Monat in den Hodensack, so dass am Ende des embryonalen Lebens der Descensus in der Regel vollendet ist. Treten nun in jener Zeit, wo die beiden Organe nahe bei einander liegen, Verwachsungen ein, so ist es natürlich, dass der Descensus testis auch einen gewissen Einfluss auf die Lage des Cöcum ausüben muss. Wie einerseits nach vielen Beobachtungen infolge von abnormen Verbindungen zwischen Hoden und den nächstgelegenen Eingeweidepartien oder zwischen Letzteren und den Saamengefässen der Hoden in seinem Descensus gehindert werden kann, so ist es andererseits auch möglich, dass der Hoden das Uebergewicht behält und Eingeweide mit sich in den Peritonealfortsatz herabzieht und auf diese Weise eine Hernia congenita bedingt. Taren etzki freilich hält ebenso wie $\mathrm{W}$ ald eyer die Ansicht für falsch, dass die Lageveränderung des Cöcum durch die Verkürzung des Gekröses und infolge der Senkung der Geschlechtsdrüse zu Stande komme. Nach ihm ist die Ortsveränderung des Colon und Cöcum nach abwärts einzig und allein in dem gleichzeitigen Wachsthum des Darmes und der Bauchhöhle be- 
gründet, dem die schnellere Entwicklung des Beckens und der Bauchwände entgegenkommt. Jene eben erwähnten Verwachsungen sind in einer ganzen Reihe von Fällen beobachtet, namentlich aber auch schon bei Embryonen, wodurch also der Einwand wegfällt, dass die Verwachsung erst nach dem Descensus testis entstanden zu sein braucht. So sagt \%. B. Kocher:

„Wrisberg hat nach Scarpa öfters schon bei Embryonen strangförmige subperitoneale Verbindungen zwischen Hoden und Blinddarm gefunden. Derselbe hat bei einem Neugeborenen einen Testikel gefunden, der nicht durch den Ring gegangen und mittelst einiger Fasern mit dem Omentum adbärent war. Lawrence erwähnt zwei Fälle von Verwachsung des Wurmfortsatzes mit dem Hoden und erklärt mit Pott Verwachsungen bei congenitalen Leistenhernien für sehr häufig, was doch wohl uur für die Hernien des Cöcnm so sehr zu betonen ist."

Und Scarpa sagt:

„Beim angeborenen Bruche ist es nıebt ungewöhnlieh, Bänder zu finden, welche den Darm oder das Netz mit dem Hoden verbinden, ob man gleich niemals Ursache hatte, zu vermuthen, dass eine adhäsive Entzündung vorausgegangen ist. Bei diesen Fällen besteht der Unterschied zwischen einem gewöhnlichen und einem angeborenen Bruch wahrscheinlich nur darin, dass die häutigen Bänder und Platten beim angeborenen Bruche schon in dem Unterleibe sich gebildet haben, ehe der Hoden herabsinkt, und viel dazu beitragen, dass mit dem Hoden auch ein Darm oder Netzstïck in die Scheidenhaut hinabgezogen wird."

Wenn wir auf die Natur dieser Verwachsungen and ihre Entstehung eingehen, so stehen uns zwei Ansichten für die Erklärung zur Verfügung.

Nach Simpson's anatomischen Forschungen kommen viele angeborene Brüche von einer Bauchfellentzündung in der fötalen Periode vor, wodurch die Verschiebungen und Formänderungen, die das Bauchfell in dieser Zeit erfährt, gehindert oder modificirt werden. Rokitansky sagt:

„Das Peritoneum ist beim Fötus häufig der Sitz von Entzündung acuten oder chronischen Verlaufs mit der Quantität und Qualität nach verschiedenen Exsudaten. Sie hat vorstechend bald den einen, bald den anderen Abschnitt des Bauchfells inne, oder sie ist eine allgemeine. Sie hinterlässt nicht nur Verdickungen des Bauchfells, sondern auch Verwachsungen der Unterleibsorgane mit einander und mit der Bauchwand, und je früher sie eintritt, desto eher kann sie unstreitig die Grundursache mancher als Bildungshemmung angesehenen Anomalien im Banche werden $\mathfrak{n}$. s. w.

Denkt man sich nun eine Peritonitis an der Oberfläche einer oder melirerer dieser Organe zu der Zeit, wo dieselben noch eine andere Lage haben, denkt man sich ferner infolge dieser Entzïndung Verklebungen, so dass dadurch ein Zusammenhängen der Flächen entsteht, so ist es klar, dass das entzïndete Organ seine Lage nicht mehr wird ändern können, 
ohne dass ein Bildungsfehler durch diese Lageveränderung die Folge sein muss; alsdann findet sich in der Regel das Organ an einer Stelle fixirt, welche es in der Entwicklungszeit rorübergehend einnehmen musste, vorausgesetzt, dass nicht die Lage durch fernere Bewegungen und Veränderungen des Organs, womit es verwachsen ist, eine Aenderung erlitten hat."

Ausserdem soll dabei die Contraction der Pseudomembranen mitwirken, die, sobald sie sich in fibröses Gewebe verwandeln, gleich dem Gewebe der Narben mebr oder minder grosse Tendenz haben, sich zusammenzuziehen. Gegen diese Annahme einer fötalen Peritonitis als Ursache jener Verwachsungen spricht sich Klein sehr entschieden aus, indem er sagt, es wäre doch höchst auffällig, wenn eine solche Peritonitis nur diese einzelnen Theile befallen sollte, oder wenn eine solche, allgemein ausgebreitet, nur Verwachsungen an diesen Stellen bedingte; auch wäre nicht einzusehen, dass eine Peritonitis foetalis den Fötus nicht zum Absterben bringen sollte. Statt dessen giebt er eine Erklärung, die einen sehr geküinstelten Eindruck macht. Er nimmt im Fötus normal vorhandene Duplicaturen des Bauchfells an, welche er von dem bereits in den äusseren Leistenring eingetretenen Hoden schräg uber den Ileopsoas und aufwärts nach der Ileocöcalgegend verlaufen sah; diese sollen im Verhältniss zum übrigen Peritoneum kein gleiches Wachsthum innehalten und späterhin als kurze und scheinbar neugebildete Stränge erscheinen. Neuere Autoren nehmen die fötale Peritonitis durchaus als wahrscheinlich an, so z. B. Virchow, B. Schmidt, Orth u. A. Die Gründe Klein's sind doch auch nicht stichbaltig. Zweifellos aber spielen peritonitische Verwachsungen in späterer Zeit eine grosse Rolle in der Fixation des Cöcum an abnormer Stelle. Der Blinddarm kann durch solche Verwachsungen mit anderen Organen in Verbindung treten, wenn er selbst oder jene für einige Zeit eine abnorme Lage haben; daraus entsteht dann ein dauernder abnormer Zustand. So sind abnorme Verwachsungen mit dem Netz beobachtet, auch mit dem parietalen Peritoneum, wie ich sie schon bei der Besprechung der abnorm gelingen Bekleidung des Cöcum mit Peritoneum erwähnt habe. Ein Zug dieses verwachsenen Organs am Cöcum kann nun dieses unter Umständen zum Inhalt eines Bruches machen. Die Wirksamkeit eines solchen Zuges konnte ich bei einer Section beobachten. Es handelte sich um einen Mann, der eine grosse rechtsseitige Hydrocele und dabei einen rechtsseitigen Scrotalbruch hatte. Dicht vor der Bruchpforte sass das Cöcum, das nur vorn und zu beiden Seiten von Peritoneum überzogen war; der Wurmfortsatz hing in die Bruchpforte hinein. Es gingen nun sebr deutliche subperitoneale Stränge von dem 
Cöcum in den Bruchsack hinein, die beim Herabhängen des schweren Scrotum stark gespannt waren, so dass also ein permanenter Zug durch das Gewicht des schweren Hodensackes stattgefunden hat. Wäre dem Manne noch einjge Zeit zu leben vergönnt gewesen, so wäre wohl aus dieser Hernia proc. vermiformis durch $\mathrm{Zug}$ eine Cöcalhernie geworden. Erstere ist gleichsam das Vorstadium der Letzteren.

Die Besprechung dieser Zugwirkung anderer Organe auf das Cöcum fübrt uns nun schliesslich zur letzten Ursache von Dislocation des Blinddarms, nämlich zu der Zugwirkung, die eintritt infolge von Dislocation anderer mit ibm in näherer Verbindung stehender Darmtheile. Ich babe dabei die Fälle im Sinne, wo Dünn- oder Dickdarm, oder Magen sich dislocirt bat und am Cöcum zerrt und dessen Lage auch verändert. So sagt z. B. Scarpa: „Wenn der Hodensackbruch von demjenigen Theile des Hiiftdarms gebildet worden ist, der nahe an dem Uebergange dieses Darms in den Blinddarm liegt, so zieht dieses Darmstïck den Blinddarm mit seinem wurmförmigen Anbang nach und nach in den Hodensack hinunter". Ausserdem sind alle die grossen Hernien mit viel Darminhalt Beweis für diese Möglichkeit. -

Wenn wir nun nach diesen mehr allgemeinen Erörterungen über die Lageveränderungen des Cöcum und ibre Ursachen auf die Beobachtungen eingehen, wo das Cöcum in bestimmtere Beziehungen zu einem Bruchsack tritt, also auf die Cöcalhernien, soweit sie in der Literatur niedergelegt sind, so ergiebt sich wohl ohne Weiteres aus der einseitigen Lage des Cöcum, dass diese Durchmusterung in der Weise gemacht werden muss, dass wir die Hernien je nach ihrer Beziehung zu den verschiedenen Bruchpforten getrennt durchforschen.

An den verschiedensten Bruchpforten finden sich Hernien, deren Inhalt das Cöcum war: im rechten Leistenkanal, im linken, im rechten Schenkelring, im Nabelring u. s. w. Keine Beobachtung konnte ich finden über eine linksseitige Schenkelhernie oder eine Hernia obturatoria. Ich habe im Ganzen 128 Cöcalbernien aus der Literatur zusammenstellen können, gewiss sind noch viel mehr beobachtet, wobl auch noch mehr beschrieben. Unter diesen sind 80 sichere Beob. achtungen von derartigen rechtsseitigen Leistenhernien niedergelegt, ausserdem 6, bei denen ich aus den Angaben nicht klar darüber werden konnte, ob die Hernie rechts oder links sass. Diesen gegenüber stehen 18 linksseitige Leistenbritche. Cruralhernien sind nur 11 veröffentlicht, sie hatten alle ihren Sitz rechts. Nabelbrüche fand ich 11, Ventralhernien 19, 1 Hernia ischiadica. Aus dieser kleinen $\mathrm{Zu}$ sammenstellung sieht man, wie ausserordentlich die rechtsseitigen 
Leistenhernien itberwiegen. Dies sehr bedeutende Ueberwiegen der rechtsseitigen Leistenhernien über die linksseitigen ist aus der Lage des Cöcum wohl ohne Weiteres verständlich. Das Verhältniss der Zahl der Leistenhernien zu der der Schenkelhernien ist das gewöhnliche. Auffallend ist nur, dass nur wenig Frauen mit Cöcalhernien behaftet sind, dass also dieses Moment zur Erhöhung der Zahl der Schenkelhernien wegfällt.

Wir gehen nun zur Betrachtung der einzelnen Bruchformen über.

\section{Rechtsseitige Leistenhernie mit Cöcum als Inhalt.}

Unter den 80 Fällen von rechtsseitigen Leistenbrüchen mit Cöcum als Inhalt können wir zunächst 2 Theile scheiden:

1. solche, welche auf angeborenen Anomalien beruhen, und

2. solche, welche später erworben sind.

Der Begriff der angeborenen Brïche muss hier so weit gefasst werden, dass wir auch diejenigen Brüche hinzurechnen, bei denen eine gewisse Disposition zum Entstehen eines Bruches angeboren ist, und zwar nicht nur eine Disposition Seitens eines Bruchsackes, sofern er eben vorhanden und offen war, sondern auch Seitens der Darmtheile. Wir rechnen also in diese Kategorie:

1. die Fälle, bei denen bei der Geburt ein Bruchsack vorhanden war, der für das Eintreten etwaiger Eingeweide offen stand; und

2. solche, bei denen infolge einer angeborenen Anomalie das

Cöcum die Fähigkeit erhalten hatte, ohne Weiteres zum Inhalt eines Bruchsackes zu werden, ganz ohne Rücksicht darauf, ob ein Bruchsack bei der Geburt vorhanden war.

Während also bei anderen Brtichen allein die Beschaffenheit des Bruchsackes für die Eigenschaft des Angeborenseins entscheidend ist, ist dies für diese Art von Brüchen nicht der Fall. Man würde vielleicht noch besser so unterscheiden:

1. angeborene Brüche (bei der Geburt schon vorhanden);

2. Brüche infolge von angeborenen Anomalien:

a) des Proc. vaginalis (Offenbleiben);

b) des Cöcum in seiner peritonealen Bekleidung, seinen Ligamenten, seinem Mesenterium;

3. erworbene Brüche.

In manchen Fällen wird es ja freilich schwer sein, zu entscheiden: Ist diese Anomalie wirklich angeboren oder später durch Entzỉndung entstanden? - Wirklich angeborene rechtsseitige Leistenbrïche mit Cöcum als Inhalt fand ich 16 bei Kindern verzeichnet, und zwar 12 
bei Knaben, 4 unbestimmt bezüglich des Geschlechts. Darunter sind 2 Föten aus dem 8. Monat, 2 Kinder sind über $1 \mathrm{Jahr}$ alt, die anderen 12 sind im 1. Lebensjabre.

Bei den meisten findet man die anatomischen Verbältnisse so, dass das Cöcum und Appendix mit dem Ende des Ileum den Bruchinbalt bildet. Gelegentlich ist etwas mehr vom Ileum in den Bruchsack getreten, was jedoch keinen principiellen Unterschied bedeutet.

Der Darm ist ganz frei, in den meisten Fällen ohne Verwachsung, ohne Beziehung zum Hoden; nur in drei Fällen fand sich eine Verwachsung und zwar des Appendix vermif. mit dem Hoden und dem Bruchsack angegeben, und in einem anderen ist notirt, dass ziemlich feste Adhäsionen dagewesen wären, ohne jedoch zu sagen, dass diese Adbäsionen nach dem Hoden gingen (4 monatliches Kind). Schliesslich wurde noch in einem Falle bemerkt, dass ein Mesocöcum und Mesocolon für das Col. ase. vorhanden war, analog dem Mesenterium des Dunndarms, mit gleicher Gefässvertheilung wie bei dem Letzteren.

Stellen wir diesen die angeborenen Fälle von Erwachsenen gegeniuber, so findet sich Folgendes in Bezug auf die Ursache der Hernien: Proc. vermif. mit Hoden verwachsen 1 mal, Strang zwischen Cöcum und Hoden in einer Peritonealfalte 1 mal, Därme mit Bruchsack verwachsen bei Ektopie des Hodens $1 \mathrm{mal}$, Colon ascendens mit hinterer Scrotalfläche verwachsen 2 mal, langgedehntes Mesocolon und Mesocöcum 2 mal. Nur bei zweien dieser Fälle ist angegeben, dass der Hoden frei gewesen sei in der Tunica, dass der Darm in einem offen gebliebenen Proc. vaginalis lag, dass also der Bruchsack ein congenitaler war. Unter den der Angabe nach nicht angeborenen Brüchen sind drei Fälle, wo Verwachsung mit dem Hoden bestand, ein Fall, wo die hintere Wand des Cöcum auf der Fossa iliaca festsass, dann vier Fälle mit aussergewöhnlich langem Mesocöcum, und in einem Fall davon waren ausser dem Cöcum und Appendix noch mehr Duinndarmschlingen im Bruchsack enthalten. Die tibrigen Fälle machen den Eindruck, als ob sie später durch Zug entstanden sind, entweder von anderen Därmen, die, in einen Bruchsack eingetreten, allmäblich das Cöcum nachgezogen haben, oder vom Bauchfell, indem das Peritoneum durch eine Hydrocele z. B. oder eine Geschwulst im Hodensack (ein Fall von $\mathrm{König}$ ) in einen Bruchsack heruntergezogen worden ist und das Cöcum nachgezogen hat. Auch in ersterem Falle könnte man meinen, dass das Cöcum durch Zug des Peritoneum heruntergetreten sei, indem ja, infolge der Erweiterung des Bruchsackes durch eingetretene Eingeweide, der Bedarf an Peritoneum grösser geworden 
ist, so dass es zweifelhaft wäre, ob es ein directer Zug des Darms, oder ein indirecter durch Vermittlung des Bruchsackperitoneum sei. Nun ist aber experimentell der Beweis erbracht, dass das Peritoneum sehr dehnbar ist; es bleibt deshalb fraglich, ob nicht in der 2. Gruppe Verbindungsstränge zwischen Cöcum und Hoden die Ursache des Tiefertretens des ersteren sind; diese sind ja wenig dehnbar und können bei Zug an ihrem peripheren Ende, infolge von Schwererwerden des Scrotum durch irgend eine Ursache, das erstere herabziehen. Es wäre dann also eigentlich nicht das Peritoneum, was das Cöcum herunterzöge, sondern der Verbindungsstrang. Es liegt das nahe, weil man in solchen Fällen wirklich bei Zug am Hoden gespannte Stränge sieht, die vom Hoden nach dem Cöcum verlaufen. Freilich spricht für jenen Modus wieder, dass das Cöcum in diesem Falle gewöhnlich viel weniger ausgedehnt, namentlich auf der Hinterfläche, vom Bauchfell überzogen ist. Nun ist aber durchaus nicht in allen Fällen von grossen rechtsseitigen Hernien mit anderem Bruchinhalt das Cöcum etwa durch den Zug des Bauchfells so nach unten gewandert. Dadurch wird man dazu geführt, doch einen Zug eines nicht leicht dehnbaren Stranges zwischen Hoden und Cöcum als Ursache anzunehmen.

Jene beiden Formen der Cöcalhernien unterscheiden sich in ihrer anatomischen Erscheinungsweise ausserordentlich. Während nämlich bei den sicher durch Zug des Darmes entstandenen gewöhnlich das Cöcum sehr lang gefesselt ist und scheinbar ein langes Mesenterium Lat, findet bei der anderen Form gewöhnlich das Gegentheil davon statt. Der freie Theil des Cöcum ist viel kleiner als unter normalen Verhältnissen, der obere Theil des Cöcum sitzt breit auf der Hinterwand auf. Dieses Verbältniss lässt sich auf verschiedene Weise erklären. Die Erklärung dieser Erscheinung führt uns zugleich auf die Erörterung der Frage: Giebt es bruchsacklose Cöcalhernien oder nicht? Die Cöcalhernien ohne Bruchsack spielen seit langer Zeit eine nicht unbedeutende Rolle in der zugehörigen Literatur. Während man zu anderen Hernien als nothwendige Beigabe einen Bruchsack nimmt, glaubte man auf Grund einer Beobachtung von dieser Regel bei den Cöcalhernien abgehen zu müssen. Die Beobachtungen, die zu einer solehen Annahme führten, waren die, dass man gelegentlich einer Operation (Sernin) das Cöcum nicht innerhalb eines Bruchsackes fand, sondern frei von Serosa. Freilich wurde in diesem Falle nicht nachgewiesen, dass überhaupt kein Bruchsack vorhanden war, sondern dass nur an der betreffenden Einschnittsstelle der Bruchsack fehlte. Es halten deshalb einige Autoren iberhaupt den Nach- 
weis noch gar nicht fur erbracht, dass es bruchsacklose Cöcalbernien giebt. So sagt z. B. Tuffier dariber:

„Les plus probants sont ceux de Steiger de Lucerne, de Heulard d'Arcy et de Cabaret. Mais ces anteurs s'appuient sur ce seul fait: ouverture de l'intestin sans ouverture du sac. Leurs conclusions sont recusables; d'abord le sac a pu être latéral de plus il peut s'agir d'une hernie simplement adberente."

B r oc a dagegen führt unter Cöcalhernien eine Gruppe an, die er so charakterisirt: „L'intestin lui-même peut subir une aberration de développement". Dann kann es einen congenitalen Bruch ohne Sack geben.

Je puis en conclure que si dans une hernie contenant le coecum ou trouve l'appendice ou l'intestin grêle dépourvu de séreuse, on peut conclure à une malformation congénitale, puisqu'il n'est pas possible de dépouiller ces organes de leur péritoine.

Diese Missbildung ist sebr selten; v. Bardeleben, Trèves fanden unter 300 Leichen keinen einzigen Fall von développement caecal extrapéritonéal, und unter 43 Fällen von Appendixhernien sind nur zwei Fälle (Cabaret, Richet), wo er sans revêtement séreux war, doch sind das nur Beobachtungen bei Operationen ohne weitere Untersuchungen. Im Fall Sernin war vielleicht doch Serosa da. Congenitale Hernien können vielleicht ohne Sack sein bei congenitaler Missbildung; alle später entstandenen Brïche haben einen vollständigen Sack, die gegentheiligen Beobachtungen sind nicht gentigend begründet.

Tuffier sagt in einer Discussion daruber: „Il n'existe qu'une observation due à Sernin où la bernie n'avait pas de sac", und Schmidt spricht sich noch entschiedener dagegen aus, indem er sagt: „Dass der Blinddarm ganz ohne Bauchfellüberzug und sonach auch nebenliegenden Bruchsack herabtrete, kommt wohl nicht vor, obwohl sich diese Meinung von Autor zu Autor fortgepflanzt hat". - Wenn wir diese sogenannten Brüche ohne Bruchsack znsammenbalten mit den Cöcalhernien, bei denen das Cöcum, nur noch zum Theil von Peritoneum bekleidet, die Hinterwand des Bruchsackes bildet, so scheint es mir das Plausibelste, dass dies nur Uebergänge sind. Und zwar giebt es zwei Möglichkeiten, die beide etwas für sich haben. Durch Zug wird das Cöcum nach unten dislocirt, und zugleich wird das Bauchfell rom Cöcum allmählich abgezogen. Je nach der Ausdehnung dieses Processes findet man entweder das Cöcum noch im Abdomen vor der Bruchpforte, zum grössten Theil fest auf die Unterlage geheftet, im Bruchsack den Proc. vermiformis, oder das Cöeum sebon in dem Bruchsack, jedoch der von Peritoneum liberkleidete Theil 
sebr klein, oder schliesslich einen Bruchsack, dessen hintere Wand die vom Serosa bekleidete Vorderwand des Cöcum bildet, während gar kein allseitig von Bauchfell umkleideter Theil des Cöcum mehr vorhanden ist. Von der Seite gesehen wïrden sich diese ganz schematisch gezeichneten Stadien etwa so ausnehmen:
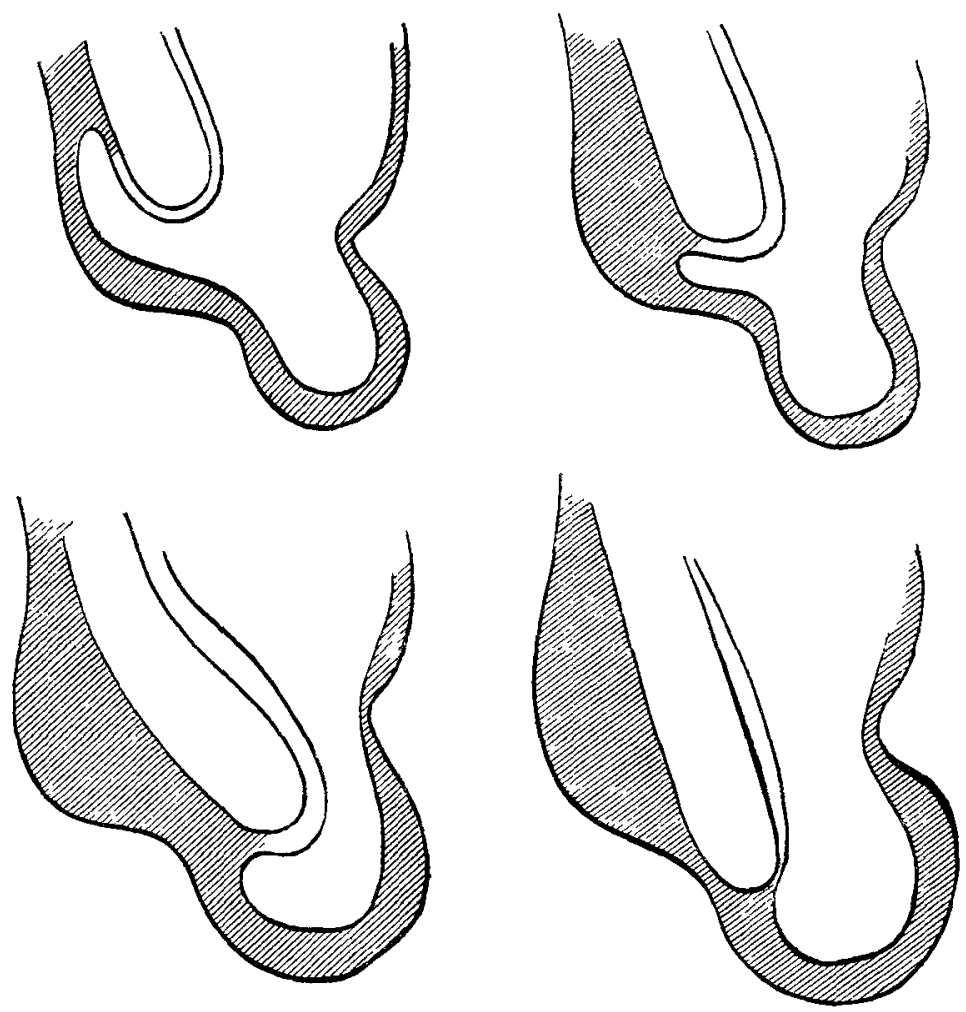

Es erscheint uns, als ob sich so durehaus zwanglos eine Continuität in der Entwicklung ergäbe, auf Grund deren die sogenannte bruchsacklose Hernie nur der am meisten ausgebildete Grad jener anderen Form ist. Bei dieser Auffassung würden sich die Fälle von Sernin, Schmidt dadurch erklären, dass man durch einen etwas mehr nach aussen gelegten Schnitt bei etwas verdrehtem Darm den Darm an einer Stelle eröffnen kann, wo kein Peritoneum ist, dass Letzteres dann als geschlossener Sack nach innen zu liegen bleibt. Ob man nun diese Hernie eine bruchsacklose Hernie nennen will, scheint mir nur ein Streit um ein Wort zu sein. Es ist jedenfalls 
bei der Entstebung der Hernie ein Brucbsack gebildet, der freilich in so eigenthümlicher Weise mit dem Darm verbunden sein kann, dass der Letztere nicht im, sondern neben dem Bruchsack liegt, freilich auf das Innigste mit demselben verbunden. Den Inhalt des Bruches kann ein anderer Darm bilden. Diese Erklärung der eigenthümlichen Veränderung in der peritonealen Bekleidung des Cöcum hat entschieden etwas für sich, sie erscheint plausibel. Andererseits muss man sicb doch fragen: Ist es wahrscheinlich, dass das Bauchfell in dieser Weise allmählich vom Cöcum abgezogen wird? Broca hält es für unmöglich. Nun lässt sich ja jene Erscheinung auch so erklären, dass die Hinterfläche des Cöcum allmählich immer mehr mit dem Peritoneum der Beckenwand verklebt, wie ich dies schon früher besprach, und dass dieses so hinten vollständig verwachsene Cöcum bei Vergrösserung des Bruchsackes durch Zug herunterkommt. Die äussere Erscheinung ist dann dieselbe wie im ersten Falle. In dem früher Mitgetheilten sind die Gründe angegeben, warum diese letztere Erklärung wohl Anspruch auf Güjtigkeit hat.

Auf eine Frage müssen wir noch eingehen: Wann entsteht diese Art von Bribehen? Sind es congenitale oder erworbene? Wie aus den vorher angeführten Aeusserungen verschiedener Autoren hervorgeht, ist die Ansicht die geltende, dass sie auf congenitaler Missbildung beruhen. Dass der Bruchsack gelegentlich vielleicht ein congenitaler ist, obgleich ich darïber keine Angaben gefunden habe, dass vielleicht auch die Blinddärme, welche von vornberein keinen sehr grossen freien Theil hatten, besonders diese Art von Brüchen bilden werden, halte ich durchaus für annehmbar; insoweit wiirde ich gegen die Annahme, dass diese Brüche congenital seien, nichts haben; die eigentliche Entstehung der Cöcalbrüche, das Herabtreten des Cöcum, das Eintreten in den Bruchsack $\mathfrak{u}$. s. w., das glaube ich durch mechanische Momente, durch Zug veranlasst, der ebenso gut, ja wohl immer erst nach der Geburt eintritt. Ich möchte erwähnen, dass diese Form der Cöcalbrïche in ihren verschiedenen Graden nur bei Erwachsenen beobachtet ist. Unter den Cöcalhernien bei Kindern ist kein Fall, der diese Form gehabt hätte, und unter den Fällen von Erwachsenen ist keiner, wo die Angabe gemacht wäre, dass der Bruch schon von Kindheit an bestanden bätte. Da die Zahl dieser Hernien keine kleine ist, so unterstützen auch diese Momente meine Annahme, dass sie nicht die Folge einer congenitalen Anomalie sind. Es bleibt mir nur noch die Frage zu erledigen: Wie und wodurch wird dieser Zug ausgeitbt? In einem Falle, welcher von uns beobachtet wurde, war es zweifellos eine Hydrocele, die durch ihr Gewicht die Bildung eines 
Brucbsackes und dadurch mit Hülfe von Zug das Herabtreten des Cöcum veranlasste.

In gleicher Weise kann naturlich auch die Ausdehnung eines Bruchsackes durch Eintreten von Eingeweiden wirken; es wird Peritoneum gebraucht. Auch eine kurze Verbindung zwischen Cöcum und Hoden kann dieses Herabtreten des Cöcum in derselben Weise zur Folge haben, wenn der Hoden daran zieht. Es lässt sich dieses Moment nicht für jeden Fall nachweisen, weil hierfür die Angaben nicht genau genug sind.

\section{Linksseitige Cöcalbrüche.}

Zunächst hat das Vorkommen linksseitiger Cöcalhernien etwas Auffallendes. Vergegenwärtigt man sich aber jene früher erörterte Möglichkeit der Lageveränderungen des Cöcum, so wird es ohne Weiteres verständlich. Ebenso ist es sofort klar, dass die Ursachen für diese viel weniger mannigfaltig sein können, und dem entsprechen auch die thatsächlichen Beobachtungen. Die Angaben darüber lauten folgendermaassen: Bei Neugeborenen wurden keine beobachtet, jedoch sind 4 Fälle von Kindern mit linksseitigen Cöecalbrüchen beschrieben; davon enthielten 2 blos Cöcum und Appendix, einer noch Dünndarmschlingen; eine Ursache ist bei ibnen nicht angegeben; in 3 Fällen von Erwachsenen ist die Angabe gernacht, dass ein langgedehntes Mesocolon und Mesocöeum vorbanden war, in einem Fall bei gleichzeitig bestehender Kyphose. Bei 2 Fällen, die auch blos Cöcum und Appendix enthielten, ist keine Angabe uber die mögliche Ursache gemacht. 1 Fall (unserer) ist nicht klar, während die übrigen 8 Fälle Brüche waren, die eine grössere Menge Darm enthielten, bei denen das Cöcum blos secundär zum Bruchinhalt wurde.

Es ergiebt sich also hieraus, dass für die linksseitigen Leistenhernien im Wesentlichen zwei Ursachen Geltung haben:

1. Es ist infolge einer angeborenen Anomalie das Cöcum abnorm beweglich und frei infolge eines langen Mesocöcum, Mesocolon und abnormer Länge der Ligamente, es kann dann unter den gleichen Bedingungen Bruchinhalt werden, wie eine Dünndarmschlinge. Hierher gebören die Brüche, wo im Wesentlichen Cöcum und Appendix im Sacke liegen.

2. Es ist das Cöcum durch Zug eines beweglichen Darmtheils oder Netz dislocirt und beweglich geworden und dann, diesem directen Zug folgend, in den linken Leistenbruchsack eingetreten.

$\mathrm{Zu}$ der letzten Kategorie hat man wohl alle die Brüche zu zählen, wo der Bruchsack ausser Cöcum noch viel Darm enthält. Frei- 
lich ist es auch möglich, dass in diesen Fällen das Cöcum infolge eines langen Mesocolon in den linken Bruchsack getreten ist und dann erst das Herabtreten der anderen Eingeweide zur Folge gehabt hat. Schliesslich bleibt uns noch die Möglichkeit des Situs transversus zu erwähnen übrig.

Wegen der Seltenheit der Fälle möchte ich den in der hiesigen Klinik beobachteten Fall ausführlich mittheilen:

Dehne, Ferdinand, 25 jähriger Ackersknecht aus Hemering bei Hameln, aufg. 22. Mai 1890. Patient hat von Jugend auf eine Anschwellung der linken Hälfte des Scrotum, die in dem letzten halben Jahre an Umfang sehr zugenommen hat.

Status: Es besteht eine strausseneigrosse Anschwellung der linken Hälfte des Scrotum, die sich nach oben in die Gegend des Leistenkanals fortsetzt. In der unteren Spitze fühlt man vorn isolirt den Hoden. Die Geschwulst fluctuirt deutlich, lässt sich nicht durchleuchten, Abschnürfurche fehlt ebenfalls. Der Inhalt lásst sich nicht in die Bauchhöhle zurückdrängen.

23. Mai Operation in Narkose.

Längsschnitt über die linke Scrotalhälfte bis in die Tunica vaginalis. Letztere sehr stark verdickt. Beim Durchschneiden entleeren sich etwa $200 \mathrm{Ccm}$. einer klaren, bernsteingelben Flïssigkeit, und gleichzeitig legt sich eine Darmschlinge in den Schnitt vor, die sich nach Erweiterung des Schnittes als $\mathrm{Cö} \mathrm{cum}$ mit Proc. vermif. erweist. Darm stark aus. gedehnt, hochroth gefärbt, lässt sich erst, nachdem die Darmgase durch Druck entfernt sind, durch den Leistenring in den Bauch zurückschieben. Dünne Verwachsungen wurden vorher stumpf getrennt. Die Tunica vagin. ist stark verdickt, auf ihrer Hinterfläche verläuft der stark mit Gefässen versehene, plattgedrückte Samenstrang, unten liegt der Hoden, dessen Contouren wegen der dicken Tunica nicht genau zu sehen sind. Dann wird der offen gebliebene Processus vagin. am Leistenring in sich durch dicke Catgutnähte vernäht und schliesslich im oberen und unteren Wundwinkel die äussere Haut mit der Tunica durch Catgutnähte vereinigt, während die Mitte frei bleibt. Höhle mit Jodoformgaze ausgestopft. Watteverband. Guter Verlauf. Heilung.

\section{Rochtsseitige Cruralhernien.}

Die Zahl der Cruralbernien ist gering. Im Ganzen habe ich 11 Fälle gefunden und zwar nur von Erwachsenen. Von 8, bei denen das Geschlecht angegeben ist, sind 5 Frauen, was ja bei der Neigung der Frauen zu Cruralhernien nichts Ueberraschendes hat. Sie sind alle spät entstanden, in den meisten Fällen waren Verwachsungen zwischen Darm und Bruchsack vorbanden und in 1 Fall ein sebr langes Mesenterium des Colon ascendens nebst Verlängerung des Lig. ext. coeci.

Ich möchte es für die anderen Fälle für wahrscheinlich halten, 
dass jhrer Entstehung dieselbe Ursache zu Grunde liegt, wie vielen später entstandenen Leistenbrüchen, nämlich dass das Cöcum durch Verwachsung in der Nähe des Cruralkanals fixirt und dann bei der Entstehung eines Bruchsackes mit nach unten gezogen wurde.

Aus dem, was wir über die Lageanomalien des Cöcum gesagt haben, geht hervor, dass auch noch andere Möglichkeiten vorliegen, dass anch noch andere Bruchpforten das Cöcum als Inhalt erhalten können. Eine geradezu bevorzugte Stellung nimmt hierbei die Nabelpforte ein.

\section{Nabelbrüche.}

Wenn ich von den Nabelschnurbrüchen absehe, die ja häufig einen grossen Theil der Eingeweide enthalten, darunter auch das Cöcum, so finden sich eigentliche Nabelhernien 8 bei Kindern und 3 bei Erwachsenen, und zwar 7 Neugeborene, 1 Fötus männlichen Geschlechts und ein erwachsener Mann, 2 Frauen.

In 4 Fällen von den Kindern war fast der ganze Darm in dem Bruchsack enthalten, also das Cö̈cum wohl secundär durch Zug der übrigen Därme hineingebracht worden. Dasselbe war der Fall bei den 2 Franen. Von den anderen Fällen waren 4 wohl dadurch veranlasst, dass ein langes Mesocöcum bestand, so dass eine abnorme fötale Lage nahe der Mittellinie sich erhalten hatte.

Schliesslich ist noch eine Hernia ischiadica zu erwähnen, die ausser dem Cöcum den grössten Theil des Darmes enthielt, und eine Hernia ventralis, nur mit dem Cöcum als Inhalt, für deren Entstehung sich eine bestimmte Ursache aus den vorbandenen Angaben nicht entnehmen lässt.

\section{Literatur.}

Kölliker, Grundriss der Entwicklungsgeschichte. - Hertwig, Lehrbuch der Entwicklungsgeschichte. - Henle, Handbuch d. system. Anatomie. - Hyrtl, Lehrbuch der topograph. Anatomie. - Orth, Lehrbuch der pathol. Anatomie. Rindfleis $\mathrm{ch}$, Lehrbuch der pathol. Anat. - v. Bardeleben, Virchow's Arch. Bd. II. - Luschka, Virchow's Arch. Bd. VI. - Wenzel Gruber, Arch. f. Anat. u. Physíol. 1862. - Der selbe, Bulletin de l'Académie imp. de scienc. d. St. Pétersbourg. T. V. - Derselbe, Virehow's Areh. Bd. XLIV u. XLVIL. - Roser, Roser's Archiv. 1843. - Derselbe, Lehrbuch der anatom. Chirurgie. - Derselbe, Vademecum. - Tarenetzki, Mémoires de l'Académie imp. de scienc. d. St. Pétersbourg. T. XXVIII. p. 7. - Toldt, Wachsthumsveränderung des Gekröses des menschlichen Darmkanals. Denkschrift der kaiserl. Akademie der Wissenschaften. 
Wien 1879. - Schiefferdecker; Arch. f. Anat. u. Physiol. 1882 u. 86. - Walde yer, Virchow's Arch. 1874. - Virchow, Virchow's Arch. Bd.V. - C. Langer, Die Peritonealtaschen am Cöcum. Zeitschr. d. Gesellschaft der Aerzte in Wien 1862. - Scarpa, Ueber die Brüche. - Di effenbach, Operat. Chir. Bd. II. - Treitz, Hernia retroperitonealis. Prag 1857. - A. Cooper, Vorlesungen über Herníen. B. Schmidt, Unterleibsbruche. 1892. - Graser, Unterleibsbrüche. 1891. - Tuf fier, Bullet. d. sociét. anat. 1886. - Krönlein-Brunner, Beitr. zur klin. Chir. - Malgaigne, Yorlesungen über Hernien. - Ko cher, Gerhardt's Handb. Bd. IV. der Kinderkrankheiten. - Mérigot de Treigny, Étude sur les hernies du gros intestin. Th. Paris 1886. - Pfis ter, Anatomie u. Therapie der Blinddarmbrüche. Diss. Zürich 1883. - Klein, Ueber die Brüche des Proc. vermiform. coeci. Diss. Giessen 1868. - Thurn, Von den Brüchen, welche mit Aberration der Lage des Hoden u. s. w. Diss. Giessen 1868. - Chiari, Prager med. Wochenschr. 1888. Bayer, Prag. med. Wochenschr. 1881. - Riedel, Th. Wette, Die Herniotomien im städt. Hospital zu Aachen. Diss. Jena 1889. - v. A rx, Cöcum in einer linksseitigen Scrotalhernie. Correspondenzbl. f. schweiz. Aerzte. 1886. - L e bert, Journ. d. connaissances méd. et chir. 1838. - Gray, Lancet 1888. - Broca, Hernie inguinale congénitale du coec. Soc. anat. 1887. - Boiffin, Hernie adhérente au sac. Th. Paris. - Aldebert, Hernie inguinale droite du coecum. Soc. anat. 1887. - Sandifort, Icon. herniae congenit. - Chaput, Hernie crurale droite etc. Soc. anat. 1887. - Guillet, Hernie inguinale droite du coec. 1887. - A lexandre, Bull. de Soc. anat. 1886. - Faraboeuf, Bull. de Soc. anat. 1885. - Wris berg, Observat. anat. de tectu descens. - K raussold, Volkmann's Sammlung klin. Vortráge. Nr. 191. 1881. - M archant, Bull. de Soc, anat. Marchant. 1887. - Paget, 3 Fàlle von eingeklemmten Cöcalhernien bei Kindern. Lancet 1890.

\section{Inguinalhernien bei Kindern.}

Klein. Kind. Präparat. Angeboren, rechts. - Cöcum mit Appendix und kleines Stück des anstossenden Ileum. - Darm frei, nicht mit dem Hoden verwachsen.

Klein. Kind. Präparat. 3/4 Jahre. Angeboren, rechts. - Cöcum mit Appendix nnd kleines Stiick des anstossenden Ileum. - Darm frei, nicht mit dem Hoden verwachsen.

Sandifort. Knabe. Einige Tage alt. Angeboren, rechts. - Cöcum mit Appendix und Ende des Ilenm. - Proc. vermiformis mit Bruchsack und Hoden verwachsen.

Czerny. Knabe. 10 Jahre. Angeboren, rechts. - Cocum mit Proc. vermif., etwas Dünndarm. -- Darm frei.

v. Wahl. Knabe. 8 Monate. Seit 3 Monaten, rechts. - Cocum mit Appendix nnd etwas Dünndarm. - Cöcum frei beweglich, nnverwachsen, Bruchsack neugebildet, nicht persistent. Proc. vagin.

Ricke. Kind. 4 Monate. Angeboren, rechts. - Dünndarmschlinge mit Cöcum. - Ziemlich feste Adhäsionen unterhalb des Hoden ebenfalls im Bruchsack.

v. Wahl. Knabe. 8 Jahre. Rechts. - Cöcum mit Appendix. (?)

Fé ré. Knabe. 1 Jahr. Angeboren, rechts. - Cöcum mit Appendix und $24 \mathrm{Cm}$. Dünndarm. - Frei, ohne Zusammenhang mit dem Hoden. 
Féré. Knabe. 4 Monate. Angeboren, rechts. - Cöcum und Appendix mit dem Dünndarm. - Proc. vermif. am Grunde des Bruchsackes verwachsen.

Riedel. Knabe. 9 Monate. Seit 5 Monaten, rechts. - Cöcum mit Proc. vermif. und etwas Dündarm. - Cöcum frei, ebenso der tibrige Darm.

Sandif ort. Kind. 3 Monate. Angeboren, rechts. - Cöcum mit Appendix. - Appendix am Hoden und Bruchsack befestigt und an erster Stelle dicht und fester als normal.

Sandif ort. Kind. 6 Monate. Links. - Cöcum.

Chanjan. Kind. 3 Monate. Links. - Cöcum mit Appendix.

Spengler. Knabe. 51/2 Jahre. Angeboren, links. - Cöcum mit Appendix und ein Convolut Dünndarmsehlingen.

Mérigot de Treigny. Männlich. 71/2 monatlicher Fötus. Angeboren, rechts. - Cöcum und $31_{12} \mathrm{Cm}$. Dünndarm. - Keine Adhäsion. Cöcum und Theil des Col. asc. frei und flottirend, nur durch ein Mesocöcum gehalten, entsprechend dem Dündarm.

B r oca. Männlich. 7 monatlicher Fötus. Angeboren, rechts. - Cöcum mit Appendix. Ausserdem noch Colon und Ileum. - Cöcum hat einen vollständigen serösen Ueberzug. Gedärme unverwachsen.

Gaillard. Cöcum.

How ard. Kind. Links. - Cöcum.

Paget. Kind. 1 Jahr. Rechts. - Cöcum, etwas Dünndarm und Netz. - Besonderer Bruchsack.

$\mathrm{P}$ a g e t. Kind. 3 Monate. Rechts. - Cöcum mit ungewölhnlich langem Proc. vermif. - Tunica vay. getrennt vom Bruchsack.

\section{Leistenhernien bei Erwachsenen.}

Pott. Mann. 17 Jahre. Angeboren, rechts. - Theil des Ileum, Cöcum mit Proc. vermif. - Proc. vermif. mit Hoden und Nebenhoden verwachsen.

Wrisberg. Mann. (?) Angeboren, rechts. - Dünndarm, Col. asc., Cöcum. - Vom Cöcum ein dicker fibröser Strang in einer Peritonealfalte zum Hoden verlaufend.

Guill et. Mann. 43 Jahre. Angeboren, rechts. - Cöcum und $50 \mathrm{Cm}$. Ileum. - Cöcum mit seiner Hinterfläche mit dem Bruchsack verwachsen. Ektopie des Hoden. Hoden nieht zu finden.

K rönlein. Mann. 39 Jahre. Angeboren, rechts. - Cöcum mit Proc. vermif. - Hoden frei im Bruchsack. Col. ascend. mit der hinteren Fläche durch Bindegewebe an die innere Scrotalfläche geheftet.

Pfister. Frau. 41 Jahre. Angeboren, links. - Colon ase. Cöcum und Proc. vermif. - Langgedehntes Mesocolon, Mesocöcum. Eingeweide sehr beweglich.

Brunner. Mann. 44 Jahre. Von Jugend an, rechts. - Netz, Cöcum mit Proc. vermif., $6 \mathrm{Cm}$. Col. ascend. - Hinten und aussen mit dem Bruchsack verwachsen.

Riedel. Mann. 73 Jahre. Immer, rechts. - Cöcum mit Proc. vermif. Dünndarm. 
König. Mann. 25 Jahre. Von Jugend an, links. — Cöcum mit Proc. vermif. - Tunica bas. test. prop. bildet den Bruchsack.

v. A rx. Mann. 82 Jahre. Von früher Jugend an, links. - Cöcum mit Proc vermif. Anfang des Col. ascendens, ganze Dünndarm. - Langes Mesocolon. Doppelseitge Hernie (rechts Colon). Kyphose.

Scarpa. Mann. 26 Jahre. In der Kindheit schon bestehend, rechts. - 4 Fuss Ileum, eine Portion Colon, Cöcum und Appendix. - Hoden blossliegend, daher Bruch angeboren, Riss im Cöcum.

Schuh. Mann. 55 Jahre. 12 Jahre, rechts. - Cöcum mit Proc. vermif. - Nekrose des Proc. vermif.

Brya nt. Mann. Junger. Rechts. - Cöcum und etwas Dünndarm. - Leichte Reposition.

Scarpa. Mann. 50 Jahre. Rechts. - Cöcum. - Grund des Cöcum frei beweglich im Bruchsack, die Befestigungspunkte des Cöcum nur wenig heruntergesunken.

Kraft. Mann. 76 Jahre. Rechts. - Cöcum mit Appendix.

Reisel. Mann. 21 Jahre. Rechts. - Cöcum mit Appendix.

Brunner. Mann. 51 Jahre. 6 Jahre, rechts. - Cöcum mit der Ileocöcalklappe, Proc. vermif., eine Dünndarmschlinge.

Richet. Mann. 60 Jahre. 20 Jahre, rechts. - Cöcum. - Cöcum sehr beweglich, ohne Mesocöcum weit dislocirbar.

Vedié. Mann. Mehrere Monate, rechts, - Cöcum und Netz. Reduction leicht, jedoch grosse Tendenz zur Wiederherstellung der Hernie.

Ald e bert. Mann. 69 Jahre. 30 Jahre, rechts. - Cöcum, Col. ascend., etwas Dünnd. - Mehrere Bruchsäcke. Cöcum vollständig von Serosa bekleidet, jedoch verwachsen.

Hunter. Mann. 40 Jahre. Rechts. - Cöcum. - Keine Spur von Appendix.

Authenrieth. Rechts. - Cöcum. - Kein Appendix.

Git $n$ ther. Mann. 80 Jahre. Rechts. - Cöcum mit Proc. und ein Theil des Ileum.

Klein. Mann. Rechts. - Cöcum mit Proc. Theil des Ileum. Anfang des Col. ascend. - Der blindsackförmige Theil des Cöcum frei. Hoden deutlich geschieden.

Gray. 3 Fälle bei Erwachsenen. Rechts.

Authenrieth. Frau. Rechts. - Cöcum, kein Appendix. - Kein Appendix.

Dieffenbach. Frau. 60 Jahre. Viele Jahre, rechts. - Cöeum mit Appendix.

Gray. Mann. 30 Jahre. Seit 6 Jahren, links. - Cöcum, Wurmfortsatz, 3 Zoll Ileum.

Scarpa. Mann. Rechts. - Cöcum und Appendix. Anfang des Col. ascendens. - Von der äusseren Seite des Bruchsackhalses verbreiten sich die häutigen Falten und Ränder in gleicher Weise wie in der Unterleibshöhle.

Scarpa. Mann, 60 Jahre. Rechts. - Cöcum und Appendix. Anfang des Col. ascendens und Ende des Ileum.

x Cloquet. Mann, 60 Jahre. Rechts. - Cöcum und Appendix. Hernie en bissac, oben Cöcum, unten Appendix, dies am Grund des Sackes adhärent. 
Rizzoli. Mann. Seit vielen Jahren. Rechts. - Cöcum. - Hinterwand des Cöcum mit der Unterlage und Umgebung verwachsen.

Stanley. Mann, 66 Jahre. 4 Monate. Rechts. - Cöcum mit Appendix. - Cöcum vorn frei, hinten sehr stark befestigt durch seine Verbindung mit dem Peritoneum, welches selbst eine Strecke weit aus seiner natürlichen Verbindung herabgetreten war.

Cloquet. Mann, alt. Rechts. - Cöcum. - Cöcum zum grossen Theil von Peritoneum entblösst. Nur die vordere Seite sieht in den Sack hinein.

B. Schmidt. Mann, alt. Rechts. - Cöcum, grosse Mengen Dünndarm. - Cöcum war an seinem vorderen Umfang vom Bauchfell überzogen, von seiner Spitze aus bis zum Grunde des Bruchsackes verläuft eine kammförmige Bauchfellduplicatur.

$\times$ B. Sch mid t. Mann, 55 Jahre. Rechts. - Cöcum. - Cöcum an seiner hinteren Wand nicht vom Bauchfell überzogen, um seine Axe gedreht, derart, dass es sich um einen bruchsacklosen Bruch zu handeln schien. Doch fand sich ein nachgezogenes Stück Bauchfell, eine Furche bildend, in welcher Dunadarm lag.

Brunuer. Mann, 44 Jahre. Von Jugend an. Rechts. - Cöcum mit Proc. vermif. $6 \mathrm{Cm}$. Col. ascend. - Unten und aussen Cöcum mit dem Bruchsack verwachsen.

Clark. Mann, 76 Jahre. Seit 20 Jahren. Rechts. - Cöcum mit Appendix. - Processus fest verwachsen mit der hinteren Wand des Bruchsackes vermittelst alter Adbärenzen.

Gunter. Rechts. - Cöcum. - Doppelte rechtsseitige Hernie, vordere mit enorm verdicktem Bruchsack, der mit den in ihm enthaltenen Darmschlingen verwachsen war, dahinter als zweiter Bruch ohne Bruchsack eine Vorlagerung des Cöcum.

M urion. Cöcum mit einer Partie des Dickdarms. - Darm adhärent am oberen Theil des Sackes. Hydrocele.

Follet de Lille. Mann, 30 Jahre. Mehrere Jahre. Rechts. - Cöcum mit Proc. vermif, einige Centimeter. Ileum. - Die hintere und untere Wand des Cöcum in inniger Verbindang mit dem Bindegewebe der Hinterwand.

Lab orde. Mann, 48 Jahre. Ueber 20 Jahre. Rechts. - Cöcum mit Proc. vermif. Endtheil des Ileum. - Cöcum frei, nur ganz leichte Adhärenzen. Das Cöcum bildet jedoch nicht den Inhalt des Sackes, sondern es liegt fest auf der Hinterwand, durch Bindegewebe fixirt.

B a y er. Mann, 27 Jahre. Seit 5 Jahren. Rechts. - Cöcum mit Proc. vermif. unterster Theil des Ileum. - Das Cöcum bildet die Hinterwand des Bruches.

Cloquet. Mann, 50 Jahre. Rechts. - Cöcum. Heumschlingen. Cöcum mit einem vorderen, seitlichen Bruchsack, in welchem die Ileumschlinge liegt.

Demeaux. Mann, 55-60 Jahre. Rechts. - Cöcum, eine Dünndarmschlinge. - Cöcum statt in der Fossa iliaca auf der Abdominalwand placirt, nur auf einer Seite mit Peritoneum bekleidet. Das Cöcum hat einen Bruchsack gebildet, in welchem die Ileumsehlinge lagert.

Cappa. Mann, 51 Jahre. Rechts. - Cöcum mit Proc. vermif. $8 \mathrm{Cm}$. Ileum. - Die Ileumschlinge liegt in einem Sack vor dem Cócum, welches die Hinterwand des Sackes bildet. Reduction schwierig. 
Ricard. Mann. Rechts. - Cöeum mit Appendix, $15 \mathrm{Cm}$. Ileum, untere Partie des Col. ascend. - Cöcum hat einen Sack gebildet, in welchem die Ileumschlinge liegt.

Zsismondy. Frau, 45 Jahre. Rechts. - Cöcum. - Vorlagerung der Blinddarmwand. Kothabscess.

Adams. Cöcum. Dünndarmschlinge. - Scheinbar kein Bruchsack, d. h. derselbe lag hinter dem Blinddarm und enthielt ausser dem eingestïlpten Theil des letzteren noch eine Dünndarmschlinge.

Verneuil. Rechts. - Cöcum. - Nur an der vorderen Seite des eingeklemmten Blinddarms ein Bruchsack.

Ma n ec. Mann, 19 Jahre. Rechts. - Cöcum. - Cöcum im Bruchsack, Proc. vermif. ausserhalb des Bruchsackes.

Sernin. Mann. Rechts. - Kein Bruchsack. Colon ascend. in der Fossa iliaca gesenkt an der Stelle des Cöenm. Cöcum tiefer. Proc. vermif. und Ileum im Innern des Peritoneum. Cöcum hat kein Mesocöcum.

Malgaigne. Mann, 73 Jahre. Rechts. - Cöcum, Appendix, Ende des Ileum. Grosser Bruch links.

Malgaigne. Mann, 60 Jahre. Rechts. - Col. ascend. Cöcum bis $3 \mathrm{Cm}$. von der Klappe. Links Ileum und Flex. iliaca.

König. Mann, 66 Jahre. Rechts. - Cöcum mit Proc. vermif. Theil des Col. ascend.

Patholog. Institut Götingen. Mann, erwachsen. Rechts. Cöcum, Anfang des Colon, Ende des Ileum. - Grosser Sack dentlich heruntergezogen. Hoden (?) nicht gefunden.

Luschka. Links. - Cöcum nebst Portion des Dünndarms durch den linken Leistenkanal getreten und zum Inhalt eine sehr umfänglichen Hernia inf. sin. geworden.

* Scarpa. Mann. - Eingeweide und Hodensack um ibre Axe in der Art gedreht, dass die Verbindung derselben mit dem Bruchsack von der hinteren Seite der Geschwulst nach der vorderen hin sich gewendet hatte.

Dessault und Chopart. Sie haben nach Scarpa den Blinddarm unter der Haut des Hodensackes blossliegen sehen.

Petit. Junger Mann. Mehrere Jahre. Rechts. - Cöcum, Theil des Ileum und viel Dünndarm.

Scarpa. Mann, 30 Jahre. Lange Zeit. Rechts. - Cöcum mit Appendix durch Gangrän vernichtet. Ende des lleum, Anfang des Colon. - Die Peritonealfalten, welche die obere Partie des Cöcum und den Anfang des Colon fixiren, sind heruntergerückt.

A rnaud. Mann, 60 Jahre. 20 Jahre. Rechts. - Theil des Ileum, Cöcum und 10 Zoll Col. asc. - Dann dem Sack adhärent namentlich das Colon.

'I'rè ves. Mann, 41 Jahre. Mehrere Jahre. Rechts. - Viel Dünn darm, Cöcum. - Zahlreiche entzïndliche Verwachsungen.

Chiari. Mann, 74 Jahre. Seit 39 Jahren. Rechts. - Jejunum, Ileum, Cöcum mit Proc. vermif. Col. asc., Col. transvers. Netz.

L eroux. Mann, 54 Jahre. Sehr lange. Rechts. - Blase mit 1 Liter Urin Cöcum, Col. ascend., mehrere Dünndarmschlingen, Netz. 500 bis $600 \mathrm{Grm}$. Fluissigkeit. 
Linh art. Mann. 28 Jahre. Rechts. - Dünndarm, Dickdarm, Cöcum. -- Därme beweglich.

Méry. Mann, alt. Rechts. - In der Bauchhöhle 1 Fuss Dunndarm, alles Uebrige im Bruchsack.

Reosdin. Mann, 72 Jahre. Rechts. Grosser Theil des Dünndarms, Cöcum mil Appendix und Theil des Col. ascend. - Keine Verwachsung mit dem Bruchsack.

Dunlop. Frau, 45 Jahre. 20 Jahre. Rechts. - 1 Duinndarmschlinge. Cöcum mit Appendix. Kleine Partie Colon. - Reduction schwierig, jedoch möglich.

Frei. Frau, 47 Jahre. Mehrere Jahre. Rechts. - 4 Fuss Dünndarm, Cöcum, 1 Fuss Dickdarm. - Reduction möglich.

Herbert. Mann, 63 Jabre. Mehrere Jahre. Links. - Der ganze Dünndarm, Cöcum und etwas Col. ascend.

A lexandre. Mann, 65 Jahre. Seit 40 Jahren. Links. - 1 Meter Colon, Cöcum, Dünndarm u. s. w. - Sehr feste Adhärenzen. Nur Col. transvers. im Bauch.

Malgaigne. Mann, 79 Jahre. 3 Jahre. Links. - Sehr ausgedehnte Ileumschlinge, Cöcum. - Cöcum stark herbeigezogen von seinem normalen Platz, es hat eine Art Mesenterium.

Bradley. Mann, 63 Jahre. Lange Zeit. Links. - Zahlreiche Dtinndarmschlingen, Cöcum, Anfang des Col. ascendens.

Ca m per. Mann, alt. Links. - Cöcum mit Appendix. - Das Gewicht der dünnen Gedärme hat das Bauchfell und mithin auch das Cöcum in die linke Leistengegend sich zu senken gezwungen. Rechts auch ein Bruch

Bonn. Mann, alt. Links. - Theil des Ileum, Cöcum, Appendix, Theil des Col. ascend. - Rechts auch ein Bruch mit Col. transvers., Col. desc. und Netz.

Bonn. Weib. Links. - Netz, Partie Ileum, grosser Theil Colon, Cöcum mit Appendix. Links Ovarium und Tube.

Cloquet. Links. - Ganzer Dünndarm, Cöcum, Netz.

Le b e r t. Grösster Theil des Dünndarms, Cöcum, grosse Partie Dickdarm. Magen.

Vo ig t. Magen, Col. transvers., Col. ascend. mit Cöcum, Anfang des Col. descend.

Schindler und Steudener. Mann, 28 Jahre. Bruchanlage schon vor längeren Jahren constatirt. Rechts. - Ein Theil der linken und hinteren Fläche des Cöcum mit Appendix im inneren Leistenring. - Der übrige in das Col. ascend. ubergehende Theil befand sich in einer Höhle zwischen Musc. obl. ext. und int., dicht am Ing.-Kanal. Beim Herausziehen dieses Darmes aus der Höhle folgt demselben der Hoden, welcher mit der hinteren Fläche des Cöcum verwachsen war.

Mérig ot de Treigny. Mann, 34 Jahre. Lange Zeit. Rechts. Netz, Cöcum mit Proc. vermif., Endstiick des Ileum, was kaum in den Sack reicht. - Hintere Wand des Cöcum auf der Fossa iliaca, dicht am Eingang in den Ing.-Kanal festsitzend. Bei Zug hebt sich das Testis mit dem Darm. Directe Verbindung des Peritoneum vom Cöcum nach der Hernie.

Tuffier. Mann. Rechts. - Ende des Ileum, Cöcum und Colon 
ascend. - Ektopie inguinale ext. des Testis. Soll durch Herabsteigen des Col. asc. mit Zug desselben am Cöcum u. s. w. entstanden sein.

Czerny. Mann, 41 Jahre. 5 Jahre. Rechts. - Cöcum und Ileum. - Proc. vermif. mit dem Hoden zusammenhängend, ohne Peritonealüberzug. Bruchsack als nachgezogene Peritonealausstülpung aufgefasst.

Cloquet. Mann, 60 Jahre. Rechts. - Mehrere Dünndarmschlingen. Partie des Cöcum. - Suspendirt an einem Mesocöcum.

$x$ Billroth. Cöcum und Ditnndarmschlinge. - Beide waren doppelt gedreht, aussergewöhnlich langes Mesocöcum.

Brunner. Mann, 39 Jahre. Vor 23 Jahren. Rechts. - Cöcum mit Proc., Stück Col. ase. und Sttick Ileum. - Langes Mesocöcum, Cöcum frei in die Bruchsackhöhle hineinragend.

Brunner. Frau, 53 Jahre. Vor mehr als 20 Jahren. Rechts. Cöcum mit Proc. vermif. — Mässig langes Mesocöcum. Cöcum nirgends fixirt.

Little. Links. - Cöcum mit Proc. vermif. und einer Dünndarmschlinge. - Langes Mesocöcum.

\section{Cruralhernien.}

Steig er. Fran, 57 Jahre. Links. - Cöcum und Proc. vermif. Hernie ohne Sack.

Czerny. (?) Rechts. - Proc. vermif. mit Cöcum und Theil des Col. ascendens. - Reposition leicht.

Czerny. (?) Rechts. - Proc. vermif., Cöcum, Hoden, Ileum. - Mit der Umgebung verwachsen.

Rich et. Mann, 57 Jahre. Rechts. - Cöcum mit Appendix. - Hernie obne Bruchsack.

B uzzachi. Mann, 1 Jahr. Rechts. - Cöcum. - Durch Adbärenzen fixirt, nach Zerreissung zu reponiren, vollständig frei.

Landsberg. Mann, 41 Jahre. 6 Monate. Rechts. - Cöcum mit Appendix.

Landsberg. Frau, 50 Jahre. Lange. Rechts. - Cöcum mit Appendix. - Zahlreiche Verwachsungen des Darms mit dem Bruchsack.

Heulard d'Arcy. Frau, 46 Jahre. 1 Jahr. Rechts. - Cöcum. Reposition sehwierig durch Adbärenzen, welche es mit dem Bindegewebe hat, auf dem es ruht. Kein Bruchsack.

Chaput. Frau. Rechts. - Cöcum und Netz, Col. ascend., etwas Dünndarm. - Lig. ext. coec. sehr verlängert, $13-15 \mathrm{Cm}$., Col. ascendens hat ein Mesenterium von $12-13 \mathrm{Cm}$. Höhe.

Bu cqu oy. Frau, 29 Jahre. 5 Jahre. Rechts. - Cöcum und Netz. - Feste Verbindungen zwischen Netz und Cöcum mit den tiefen Partien des Sackes.

Bryk. Frau, 47 Jahre. Rechts. - Dünndarm, Netz, Cöcum. Seröser Ueberzug des Cöcum vollständig und allseitig ausgebildet.

Verne uil. Rechts. - Cöcum. - Adhärenzen zwischen Cöcum und Fossa iliaca.

Heulard d'Arey citirt einen zweiten, selbst beobachteten Fall von Cöcalhernie ohne Bruchsack, jedoch ohne Beschreibung.

Cooper sagt: Ich habe 1 mal das Cö cum in einem Schenkelbruch der rechten Seite angetroffen. 


\section{Nabelhernien.}

Tonné. Knabe. Neugeboren. - Fast der ganze Dïnndarm, Cöcum und das Col. ascend. - Die Därme sind an den Berührungspunkten mit dem Bruchsack verwachsen.

Moreau. Knabe. Neugeboren. - Der ganze Darm vom Duodenum bis zur Flex. iliaca.

Godlee. Knabe. Neugeboren. - Cöcum. - Cöcum hängt am Sack fest. Das Mesocöcum war 41/2 Zoll lang, das Cöcum und Col. ascend. am rechten Rand des Mesenteriums fixirt gar nicht in d. Fossa iliaca.

Me unier. Knabe. Nengeboren. - Cöcum und etwas vom Col. ascend. - Col. ascend. steigt vor dem Dünndarm nach der medianen Partie des Abdomen und setzt sich nach einigen Biegungen in das Col. transvers. fort.

Hou el. Neugeboren. - Ganze Leber, Dünndarm, Cöcum und Theil des Col. ascend. - Bei der Geburt geplatzt.

Steol e. Kind. Neugeboren. - Cöcum, Stuick Dickdarm. - Abnorme Mobilität. Leber.

Dupuy. Embryo. - Der ganze Darm und ein grosser Theil der

Sandifort. Cöcum, das sehr harte Kothmassen enthält.

B. Schmidt. Mann. Von früher Jugend an. - Cöcum.

Mo or . Frau, 60 Jahre. Längere Zeit. - Dünndarm, Dickdarm, Cöcum, Stilck Magen. - Feste Adhärenzen zwisehen Netz und vorderer Bruchsackwand.

$\times$ Quen n. Frau, 47 Jahre. Seit dem letzten Wochenbett. - Netz, Dünndarm, Cöcum mit Proc. vermif., Col. transvers. und ascend. - Proc. vermif. an der Sackwand adhärent.

\section{Hernia ischiadica.}

Papen. Frau, 50 Jahre. - Der grösste Theil des Dünndarms, Cöcum und Appendix, Colon bei 2 Flex. sigmoid.

\section{Ventralhernie.}

Paget. Kind. 3 Monate. Rechts. - Cöcum. 